\title{
Obesity treatment by Bioenterics intragastric balloon: Iranian results
}

\author{
Mojgan Foroutan (1), Maryam Ardeshiri (2)
}

(1) Research Center for Gastroenterology and Liver Diseases, Shahid Beheshti University of Medical Sciences, Tehran, Iran; (2) Rajaei Cardiovascular Medical and Research Center Tehran, Iran.

This article is distributed under the terms of the Creative Commons Attribution Noncommercial License (CC BY-NC 4.0) which permits any noncommercial use, distribution, and reproduction in any medium, provided the original author(s) and source are credited.

\begin{abstract}
We studied the effectiveness, tolerability and safety of Bioenteric Intragastric Balloon (BIB) for treatment of obesity in Iranian population. 52 patients (46 female (88.5\%), mean age: 35.5 \pm 10 , mean body weight: $107.6 \pm 25.4 \mathrm{~kg}$ ) referred to two major training hospitals in Tehran, Iran, after evaluation by a multidisciplinary team, underwent endoscopic BIB placement under unconscious sedation. BIB was removed after 6 months and patients were discharged with drug therapy and $1000 \mathrm{kcal}$ diet. Weight and Body Mass Index (BMI) were assessed at baseline, 6 months and 1 year after BIB insertion. The mean weight and BMI at baseline were 107.6 \pm 25.4 $\mathrm{kg}$ and $39.4 \pm 7.9 \mathrm{~kg} / \mathrm{m} 2 ; 6$ months after balloon placement, they were $88.7 \pm 21.9 \mathrm{~kg}$ and $32.5 \pm 7.4 \mathrm{~kg}$ and 6 months after balloon removal, they were $93.4 \pm 21.9 \mathrm{~kg}$ and $34.85 \pm 8.2 \mathrm{~kg} / \mathrm{m} 2$ respectively. The weight decline was statistically significant throughout the study and follow up with $\mathrm{p}$ value $<0.001$. The most frequent side effects were nausea and vomiting which were resolved in the majority of cases by one week. No major complications, such as death, gastric obstruction, gastric or esophageal perforation, or balloon displacement occurred in our study. BIB is a safe, effective and well-tolerated treatment of obesity, but its effects are temporary, so it should be accompanied and followed by other methods to achieve sustained weight reduction.
\end{abstract}

Key Words: Obesity, BIB, weight loss, endoscopic procedures.

Eur J Transl Myol 28 (3): 300-303, 2018

\begin{abstract}
Obesity is a complex condition with overwhelming consequences that is becoming a worldwide social and economic problem. ${ }^{1,2}$ Numerous comorbidities are associated with obesity including hypertension, type II diabetes mellitus, coronary artery disease, dyslipidemia, nonalcoholic fatty liver disease, certain cancers and increased mortality. ${ }^{3}$ The prevalence of obesity in Iran is $10.5 \%$ and $22.5 \%$ in men and women, respectively, whith an increased trend of $5.8 \%$ in men and $17.4 \%$ in women during a 14 -year period. ${ }^{4}$ Calorie-restricted diet, physical exercise and behavior modification are firstline methods to treat obesity, but these along with pharmaceutical therapy have limited efficacy for sustained weight loss in severe obesity. ${ }^{5,6}$ Weight loss surgery has shown to be the most effective method for long-term management of severely obese patients. However it is invasive, expensive and associated with severe complications, (anastomotic leak and ulcer) and with a mortality rate estimated range between 0.1 and 2.0. ${ }^{7,-10}$ Intragastric balloon placement is an alternative for bariatric surgery with a lower risk profile, in particular for subjects who are not surgical candidates. Many recent studies in various countries have shown
\end{abstract}

that Bioenterics Intragastric Balloon (BIB) placement is a safe and effective method for short term weight loss. ${ }^{11-}$

16 Although this method is popular and performed frequently in Iran, no reports have been published to date. The objective of this study is to determine effectiveness, safety and tolerability of BIB in Iranians.

\section{Materials and Methods}

The study protocol was approved by the local research ethics committee of Beheshti University of Medical Sciences. Before BIB insertion, a written informed consent was provided to all participating patients, that signed the forms before enrollment. From September 2008 to February 2011, 52 obese patients [46 female (88.5\%), mean age: $35.5 \pm 10]$ referred to gastrointestinal medicine clinic in Taleghani hospital and Imam Hussein hospital, Tehran, Iran. They were included in the study after evaluation by gastroenterologists, nutritionists and endocrinologists, independently. The inclusion criteria were: 1 . reduction of operation risk in candidates for bariatric surgery and with BMI > 35; 2. complications of obesity, specifically, type 2 diabetes mellitus, hypertension, 
dyslipidemia, etc., and with BMI > 30; 3. recurrent failure of nonsurgical methods of weight loss with BMI $>$ 30. Exclusion criteria were: BMI < 30, esophagitis, active peptic ulcer, varices, or angiodysplasia, large hiatal hernia $(>5 \mathrm{~cm})$, chronic therapy with steroids or nonsteroidal anti-inflammatory drugs, alcohol or drug abuse, previous gastric surgery, anticoagulant therapy, pregnancy, psychiatric disorders, low general health status. All patients underwent a diagnostic upper endoscopy to rule out local conditions precluding balloon placement. Those with active peptic ulcer or esophagitis were treated and were included in the study only after a second endoscopy control confirmed the successful treatment. Under unconscious sedation with Propofol and Fentanyl the Bioenterics intragastric balloon (BIB) [INAMED Corporation, Santa Barbara, CA, USA] was implanted in the stomach and inflated with a volume of $500-700 \mathrm{ml}$ sterile saline containing 10 $\mathrm{ml}$ methylene blue under direct endoscopic vision. The patients were prescribed half saline serum along with antiemethic, anti-acid and analgesic medications and were advised to follow a fully liquid low fat diet for the first three days and then continue with regular meals. All patients were given pantoprazole ( $40 \mathrm{mg} /$ day) while the balloon was in place. They were also recommended to keep on the low calorie $(1,000 \mathrm{kcal})$ diet and physical exercise. The patients were visited after one week then on a monthly basis for postplacement symptoms and complications evaluation. The BIB was removed 6 months later under endoscopy control and patients were followed up 6 months after balloon removal. Statistical analyses were performed with SPSS 15.0 software (SPSS, Chicago, IL, USA). Paired t, repeated measurement and Wilcoxon tests were used and data were expressed as mean \pm standard deviation, frequency and percentage. A $\mathrm{p}$ value of $<0.05$ was considered significant.

\section{Results and Discussion}

The present research was conducted on 52 patients (Table 1). Ten cases did not completed the 6 months of balloon in place and 6 cases did not completed the following 6 months follow up. The majority of the patients complained of nausea $(92.3 \%)$ and vomiting (75\%), that were resolved mostly in one week. Other less common side effects are listed in table 2. There was one case of early removal due to intolerance, one case of balloon rupture during placement, 2 cases of gastric bleeding, 2 cases of balloon fluid leakage, 1 case of severe gastritis, 1 case of severe esophagitis and 1 case of pancreatitis. There was no mortality, obstruction or rupture of esophagus or stomach. The mean weight and BMI before balloon placement were $107.6 \pm 25.4 \mathrm{~kg}$ ( range: $75-180$ ) and $39.4 \pm 7.9 \mathrm{~kg} / \mathrm{m}^{2}$ (range: $30.5-71.8$ ). Six months after balloon placement they were $88.7 \pm 21.9 \mathrm{~kg}$ (range 57-160) and $32.5 \pm 7.4 \mathrm{~kg}$ (range: 20.6-68.4) respectively. The mean weight and BMI reduction was $18.9 \pm 13.9 \mathrm{~kg}(0-75)$ and $6.9 \pm 4.8 \mathrm{~kg} / \mathrm{m}^{2}$

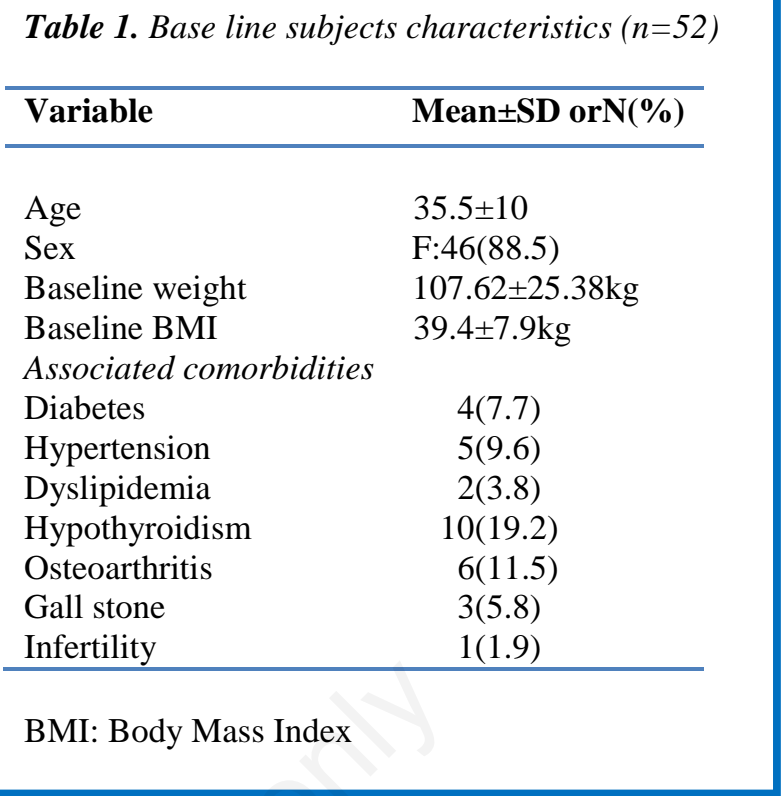

(0-25.9) with $\mathrm{p}$ value $<0.001$. Patients with morbid obesity had the highest total weight loss. For the 36 patient who completed the follow up, 6 months after balloon removal the mean body weight was $93.4 \pm 21.9$ $\mathrm{kg}$ (57-160), which was decreased $8.8 \mathrm{~kg}$ compared to the beginning of the study $(15 \mathrm{~kg}$ decrease in the first 6 months and $6.2 \mathrm{~kg}$ increase during follow up). The mean BMI at the end of follow up was $34.8 \pm 8.2 \mathrm{~kg} / \mathrm{m}^{2}$ with a $3.3 \mathrm{~kg} / \mathrm{m}^{2}$ decrease in comparison to before the balloon placement $\left(5.7 \mathrm{~kg} / \mathrm{m}^{2}\right.$ decrease during the 6 months of intervention and 2.4 increase in the follow up period). The repeated measurement test and Benferroni multiple comparison test, both showed that there is a significant difference in the mean weight and BMI before compared to 6 month after placement and 6 months after removal with $\mathrm{p}$ value $<0.001$. The Friedman test showed also that distribution of BMI differs significantly before and after balloon placement and even 6 months after balloon removal. The BioEnterics intragastric balloon is a spherical, smooth, silicone elastomer, saline-filled balloon that is resistant to degradation by gastric acid for approximately 6 months. Intra gastric balloon induces satiety by volume displacement and gastric distention and also changes gastric motility and readjust the neurohormonal milieu, eventually resulting in decrease of oral intake. ${ }^{17,18}$ Our results (18.9 $\mathrm{kg}$ and $6.9 \mathrm{~kg} / \mathrm{m} 2$, respectively) are comparable to those of a recent spanish meta-analysis of 15 studies, including 3698 patients, that estimated 14.7 $\mathrm{kg}$ weight loss and $5.7 \mathrm{~kg} / \mathrm{m}^{2}$ decline in BMI after 6 months of BIB treatment. ${ }^{19}$ On the other hand, a Cochrane database systemic review of nine randomized controlled trials, comprising 395 patients, ${ }^{20}$ showed no convincing evidence of a greater long term weight loss by intragastric balloon placement compared with conventional management. Our study showed $6.2 \mathrm{~kg}$ weight gain during 6 months follow up after balloon 


\begin{tabular}{|c|c|c|c|}
\hline \multicolumn{4}{|c|}{ Table 2. Side effects } \\
\hline Variable & $<7$ days & $>7$ days & Total \\
\hline Nausea & 57.7 & 34.6 & 92.3 \\
\hline Vomiting & 57.7 & 17.3 & 75 \\
\hline Fatigue & 9.6 & 13.5 & 23.1 \\
\hline Bloating & 5.8 & 19.2 & 25.0 \\
\hline Fullness & 1.9 & 38.5 & 40.4 \\
\hline Heart burn & 9.6 & 40.4 & 50.0 \\
\hline Early satiety & 5.8 & 32.7 & 38.5 \\
\hline Epigastric pain & 1.9 & 21.2 & 23.1 \\
\hline Diarrhea & & 3.8 & 3.8 \\
\hline Hair loss & & 17.3 & 17.3 \\
\hline Nail fragility & & 7.7 & 7.7 \\
\hline Halitosis & & 7.7 & 7.7 \\
\hline
\end{tabular}

removal, but the mean weight reduction compared to the beginning of the study was still significant $(8.8 \mathrm{~kg})$. Two recent studies in the region, Al Kahtani K, et al. in Saudi Arabia, ${ }^{16}$ and Saruc M, et al. in Turkey, ${ }^{17}$ showed mean BMI reduction of $3.6 \mathrm{~kg} / \mathrm{m}^{2}$ and $7.8 \mathrm{~kg} / \mathrm{m}^{2}$ compared to $6.9 \mathrm{~kg} / \mathrm{m}^{2}$ in our study. The procedure was safe and the majority of the side effects were mild, as was reported previously. ${ }^{20}$ None of our patients experienced major complications, such as death, gastric obstruction, gastric or esophageal perforation, or balloon displacement. The main limitations of our results are the small study sample, the lack of control group and of randomization. However, our study, that is the first report on PIP placement in Iranian population, provides valuable data on efficacy and safety of this method. The study showed, indeed, that BIB is an effective, safe, well-tolerated method for short term weight loss in Iranian population. For long term management of severe obesity, bariatric surgery remains the most effective method, but none of our patients experienced major complications, such as death, gastric obstruction, gastric or esophageal perforation, or balloon displacement In conclusion, the results of the present study show that BIB is an effective, safe, welltolerated method for short term weight loss in Iranian population. Though bariatric surgery seems the most effective method for long term management of severe obesity, larger controlled trials, including analyses of metabolic profile are recommended.

\section{List of acronyms}

BIB - Bioenterics Intragastric Balloon

BMI - body mass index

\section{Author's contributions}

Each author contributed in equal part to the manuscript.

\section{Acknowledgments}

Funding: None

\section{Conflict of Interest}

The authors declare no conflicts of interests.

\section{Ethical Publication Statement}

We confirm that we have read the Journal's position on issues involved in ethical publication and affirm that this report is consistent with those guidelines.

\section{Corresponding Author}

Maryam Ardeshiri, Department of Endocrinology, Rajaei Cardiovascular Medical and Research Center, Tehran, Iran

Phone/fax: +982122432521/+982122432517

Email: ardeshiri2003@yahoo.com

\section{E-mail of co-author}

Mojgan Forootan: mfrootan2003@yahoo.com

\section{References}

1. James WP. The epidemiology of obesity: the size of the problem. J Intern Med 2008;263:336-52.

2. Obesity: preventing and managing the global epidemic. Report of a WHO consultation. World Health Organ Tech Rep Ser 2000;894:i-xii, 1-253.

3. Fontaine KR, Redden DT, Wang C, et al. Years of life lost due to obesity. JAMA 2003;289:187-93.

4. Ayatollahi SM, Ghoreshizadeh Z. Prevalence of obesity and overweight among adults in Iran. Obes Rev 2010;11:335-7.

5. Glenny AM, O'Meara S, Melville A, et al. The treatment and prevention of obesity: a systematic review of the literature. Int $\mathbf{J}$ Obes Relat Metab Disord 1997;21:715-37.

6. Stern L, Iqbal N, Seshadri $P$, et al. The effects of low-carbohydrate versus conventional weight loss diets in severely obese adults: one-year follow-up of a randomized trial. Ann Intern Med 2004;140:778-85.

7. Silecchia G, Perrotta N, Boru C, et al. Role of a minimally invasive approach in the management of laparoscopic adjustable gastric banding postoperative complications. Arch Surg 2004;139:1225-30.

8. 8 Hauser DL, Titchner RL, Wilson MA, et al. Long-term outcomes of laparoscopic Roux-en-Y gastric bypass in US veterans. Obes Surg 2010;20:283-9.

9. Flum DR, Dellinger EP. Impact of gastric bypass operation on survival: a population-based analysis. J Am Coll Surg 2004;199:543-51.

10. Buchwald H, Avidor $\mathrm{Y}$, Braunwald $\mathrm{E}$, et al. Bariatric surgery: a systematic review and metaanalysis. JAMA 2004;292:1724-37.

11. Ganesh R, Rao AD, Baladas HG, et al. The Bioenteric Intragastric Balloon (BIB) as a 


\section{Bioenterics intragastric balloon}

Eur J Transl Myol 28 (3): 300-303, 2018

treatment for obesity: poor results in Asian patients. Singapore Med J 2007;48:227-31.

12. Lopez-Nava G, Rubio MA, Prados S, et al. BioEnterics (R) intragastric balloon (BIB(R)). Single ambulatory center Spanish experience with 714 consecutive patients treated with one or two consecutive balloons. Obes Surg 2011;21:5-9.

13. Nikolic M, Mirosevic G, Ljubicic N, et al. Obesity treatment using a Bioenterics intragastric balloon (BIB) - preliminary Croatian results. Obes Surg 2011;21:1305-10.

14. Stimac D, Majanovic SK, Turk T, et al. Intragastric balloon treatment for obesity: results of a large single center prospective study. Obes Surg 2011;21:551-5.

15. Saruc M, Boler D, Karaarslan M, Baysal C, Rasa $\mathrm{K}$, Cakmakci $\mathrm{M}$, et al. Intragastric balloon treatment of obesity must be combined with bariatric surgery: a pilot study in Turkey. Turk J Gastroenterol 2010;21:333-7.
16. Al Kahtani K, Khan MQ, Helmy A, et al. Bioenteric intragastric balloon in obese patients: a retrospective analysis of King Faisal Specialist Hospital experience. Obes Surg 2010;20:1219-26.

17. Geliebter A, Westreich S, Gage D. Gastric distention by balloon and test-meal intake in obese and lean subjects. Am J Clin Nutr 1988;48:592-4.

18. Evans JT, DeLegge MH. Intragastric balloon therapy in the management of obesity: why the bad wrap? J Parenter Enteral Nutr 2011;35:25-31.

19. Imaz I, Martinez-Cervell C, Garcia-Alvarez EE, et al. Safety and effectiveness of the intragastric balloon for obesity. A meta-analysis. Obes Surg 2008;18:841-6.

20. Fernandes M, Atallah AN, Soares BG, et al. Intragastric balloon for obesity. Cochrane Database Syst Rev 2007(1):CD004931.

Submission: May 14, 2018

Acceptance: May 24, 2018 